\title{
Preliminary feasibility testing of a planning focused CBT for adolescents with an ASD diagnosis: Suggestions for intervention adaptations to meet needs of autistic teens
}

\author{
Anouck I. Staff ${ }^{1}$, Hilde M. Geurts ${ }^{2,3}$, Marije Kuin ${ }^{4}$, Saskia van der Oord ${ }^{5,6}$, \& Bianca E. Boyer ${ }^{4,6}$
}

Published online: 27 February 2020

\begin{abstract}
Adolescents with an Autism Spectrum Disorder diagnosis (ASD) show executive functioning (EF) difficulties that are crucial to succeed in secondary school, but evidence-based EF interventions are lacking. However, for adolescents with an ADHD diagnosis such an intervention was developed, called Plan My Life (PML), which focused on enhancement of planning skills and in which motivational interviewing was integrated. We explored the applicability of PML in a sample of 12 adolescents with ASD (12-17 years). Preto post intervention parent-reported data were collected on EF problems, planning problems, and ASD characteristics. Also, qualitative analyses were conducted on therapist evaluations to investigate whether PML in its present form is suitable for adolescents with ASD and how the PML should be adjusted to better serve their needs. Reliable Change Indices showed that in general adolescents with ASD did not improve, suggesting that in its current form PML is not suitable for adolescents with ASD. However, attrition was low $(N=1)$, adolescents and parents evaluated PML positively, and a feasible list of therapist recommendations was formulated for adjustment of PML to the needs of this particular group. These recommendations seem specific to autistic teens and may be applicable to other non-pharmacological interventions that will be developed for teens with ASD to improve their care and outcomes.
\end{abstract}

Keywords Autism Spectrum Disorder • Adolescents • Planning skills • Cognitive Behavioral Therapy $(\mathrm{CBT}) \cdot$ Pilot Study

Children with an Autism Spectrum Disorder diagnosis (ASD) show executive functioning (EF) difficulties when compared to typically developing children (Demetriou et al., 2018; Geurts, Verte, Oosterlaan, Roeyers, \& Sergeant, 2004). Executive functions (EFs) are described as neurocognitive processes that enable self-control and are necessary to maintain an appropriate problem solving set to attain a future goal (Welsh \& Pennington, 1988). Children with ASD show most problems with the EFs inhibition, cognitive flexibility and planning (Geurts et al., 2004). Planning is generally defined as the process of formulating a sequence of operations intended to achieve a goal in an organized, strategic, and efficient manner (Welsh \& Pennington, 1988). In adolescence, the control and help of parents and teachers diminishes as compared with childhood, while at the same time, the transition to secondary school increases the need for EFs, particularly for planning skills (e.g., adolescents are expected to independently manage planning for long-term projects, study for tests, and complete and turn-in assignments for multiple classes on time).

\footnotetext{
${ }^{1}$ Department of Clinical Neuropsychology, Vrije Universiteit Amsterdam, The Netherlands

${ }^{2}$ Department of Brain \& Cognition, University of Amsterdam, The Netherlands

${ }^{3}$ Dr. Leo Kannerhuis, The Netherlands

${ }^{4}$ Psychologenpraktijk Kuin, Haarlem, The Netherlands

${ }^{5}$ Department of Clinical Psychology, KU Leuven, Belgium

${ }^{6}$ Department of Developmental Psychology, University of Amsterdam,

The Netherlands
}

Corresponding author Dr. B. E. Boyer, Department of Developmental Psychology, University of Amsterdam, Nieuwe Achtergracht 129B, 1001 NK Amsterdam, The Netherlands. Email: b.e.boyer@uva.nl 
Parents of adolescents with an ASD report more homework problems than parents of typically developing adolescents and the lack of planning skills contributes to the extent of homework problems. For example, disorganization of materials and problems with determining the priorities of activities appeared to contribute to the extent to which autistic students experienced homework difficulties (Endedijk, Denessen, \& Hendriks, 2011). As a result, the gap between environmental expectations and the actual ability of a child with an ASD to use their EFs widens over time (Rosenthal et al., 2013). Therefore, augmenting EFs of adolescents with an ASD, in particular planning skills, appears crucial to improve their functioning in secondary school.

Unfortunately evidence-based interventions for adolescents with an ASD focusing on high-school problems are lacking (Endedijk et al., 2011). For adolescents with Attention Deficit Hyperactivity Disorder (ADHD) such an intervention was developed, called Plan My Life (PML; Kuin, Boyer, \& Van der Oord, 2013) aiming on planning skills. PML is a cognitive behavioral therapy, containing eight individual sessions for the adolescent and two for their parents. A large-scale randomized clinical trial $(N=159)$ showed promising results: adolescents with ADHD showed significant improvement of parent-rated symptoms, EFs and impairment during the intervention (with large effect sizes), intervention drop-out was low and intervention satisfaction was high for adolescents, parents and therapists (Boyer, Geurts, Prins, \& Van der Oord, 2014). Also, effects of this planning focused CBT in adolescents with ADHD were maintained until one year after the intervention (Boyer, Geurts, Prins, \& Van der Oord, 2015).

Given that EF difficulties are present in both ADHD and ASD (Geurts et al., 2004), and because of the clear clinical need for improvement of EF in adolescents with an ASD, in this pilot-study the applicability of PML was studied in a sample of autistic adolescents. The aims of this study were: (1) to explore pre- to posttest effectiveness of PML in a sample of adolescents with an ASD to investigate whether PML in its present form is suitable for this particular group, (2) to generate a list of recommendations to adjust PML to better serve the needs of these adolescents based on qualitative analyses of intervention evaluations by the therapists. The intervention and necessary adaptations are illustrated with a clinical case example.

\section{Methods}

\section{Participants}

Schools and specialized services attended parents by e-mail on this pilot-study and interested parents were than referred by their general practitioner for this intervention. This resulted in a total group of 12 adolescents (12 to 17 years) participating in this study. All were previously diagnosed with ASD (and some with comorbid ADHD) by an independent clinician, based on DSM-IV-TR criteria (American Psychiatric Association, 2000). To assure that their intelligence level was sufficient to understand PML (i.e., total IQ is higher than 80), they at least had to attend a secondary school that in the Dutch education system is considered to be at the average difficulty level of the population (Kort et al., 2005). In our sample more participants were attending special education and education on a high level than is common among autistic students in the Netherlands (Begeer, Wierda, Venderbosch, 2013; see Table 1).

\section{Intervention}

Plan My Life (PML; Kuin et al., 2013) is a clinicbased CBT that consists of eight individual sessions for the adolescent and two for the parents (45-60 minutes each). PML focuses on planning and organizing skills that are necessary in adolescent life, with special attention for planning of schooland homework. Using a workbook, planning and organization strategies are discussed weekly (see Table 2 for the subjects per session), and the adolescent could compose the strategies he/she wanted to try the following week. Maladaptive cognitions about homework organization and strategies are assessed and are tackled using cognitive techniques.

The two parental sessions aimed at finding a balance between keeping control of their child and 
letting go, by discussing which parenting goals were worth the struggle. Next, parents were taught how to formulate and implement rules in the household and how to facilitate positive communication with the adolescent.

Table 1 Sample description

\begin{tabular}{|c|c|c|}
\hline & \multicolumn{2}{|c|}{ Total $n=12$} \\
\hline & $N$ & $\%$ \\
\hline Gender $(N$ boys $)$ & 10 & 83.3 \\
\hline \multicolumn{3}{|l|}{ Education type } \\
\hline Regular education & 3 & 25.0 \\
\hline Special education & 9 & 75.0 \\
\hline \multicolumn{3}{|l|}{ Education level* } \\
\hline Low & 1 & 8.3 \\
\hline Average & 1 & 8.3 \\
\hline Higher & 8 & 66.7 \\
\hline Highest & 2 & 16.7 \\
\hline \multicolumn{3}{|l|}{ DSM-IV ASD diagnosis } \\
\hline Autistic disorder & 3 & 25.0 \\
\hline Asperger's disorder & 4 & 33.3 \\
\hline PDD-NOS & 5 & 41.7 \\
\hline \multicolumn{3}{|l|}{ Clinical comorbidity } \\
\hline ADHD & 5 & 41.7 \\
\hline Tic disorder & 1 & 8.3 \\
\hline Dyspraxia & 1 & 8.3 \\
\hline \multicolumn{3}{|l|}{ Medication status } \\
\hline No medication & 9 & 75.0 \\
\hline Methylphenidate & 2 & 16.7 \\
\hline Antipsychotics & 1 & 8.3 \\
\hline \multicolumn{3}{|c|}{ Scores within clinical range at baseline } \\
\hline BRIEF total & 6 & 54.5 \\
\hline \multirow[t]{2}{*}{ BRIEF planning } & 5 & 45.5 \\
\hline & $M$ & $S D$ \\
\hline Age in years & 14.3 & 1.6 \\
\hline Age when diagnosed & 8.2 & 2.8 \\
\hline \multicolumn{3}{|l|}{ Number of sessions } \\
\hline Adolescent sessions & 7.7 & 1.7 \\
\hline Parents sessions & 1.3 & 1.1 \\
\hline \multicolumn{3}{|c|}{$\begin{array}{l}\text { Outcome measures at baseline (raw } \\
\text { scores) }\end{array}$} \\
\hline $\mathrm{AQ}$ & 138.3 & 11.7 \\
\hline BRIEF total & 159.3 & 18.6 \\
\hline BRIEF planning & 27.2 & 4.1 \\
\hline \multicolumn{3}{|c|}{$\begin{array}{l}\text { Outcome measures at posttest (raw } \\
\text { scores) }\end{array}$} \\
\hline AQ & 141.2 & 18.2 \\
\hline BRIEF total & 157.9 & 16.9 \\
\hline BRIEF planning & 27.9 & 4.0 \\
\hline \multicolumn{3}{|c|}{$\begin{array}{l}A D H D \text { attention deficit hyperactivity disorder; } A S D \text { autism spectrum } \\
\text { disorder; } A Q \text { Autism Quotient; } B R I E F \text { Behavior Rating Inventory of } \\
\text { Executive Function; } P D D-N O S \text { pervasive developmental disorder - } \\
\text { not otherwise specified } \\
\text { *In The Netherlands the average IQ at a low level is } \mathrm{M}=92.0(\mathrm{SD}= \\
11.7) \text {, at average level } \mathrm{M}=98.1(\mathrm{SD}=9.2) \text {, at higher level } \mathrm{M}= \\
106.9(\mathrm{SD}=10.6) \text { and } \mathrm{M}=115.6(\mathrm{SD}=11.8) \text { at the highest level } \\
\text { (Kort et al., 2005). Within these levels special education exists (i.e. } \\
\text { adapted to needs of specific groups, e.g. those with ASD diagnosis) }\end{array}$} \\
\hline
\end{tabular}

Motivational interviewing (MI) was used throughout the intervention to augment intervention motivation: (1) the adolescents chose their own intervention goals (not those of their parents or teachers), which were written down and were always visible during intervention, (2) in the first part of each session $( \pm 10 \mathrm{~min})$, the past week was discussed and attention was paid to progression towards intervention goals, (3) medication use (when relevant) and school attitude were explored on scales in a MI manner, (4) assignments were not presented as "homework", but were formulated as an experiment for the upcoming week. In that way, the adolescent was free to choose an intervention strategy that fitted his/her life and the strategy could be adjusted according to their experiences, (5) after every session, the adolescent evaluated the session on four visual analog scales regarding the therapist, importance and usefulness of the session subject, and their intention to try the new strategies, (6) whenever the adolescent was not motivated enough to finish a session, MI was conducted by discussing pros and cons of intervention until the adolescent indicated to have enough motivation for the intervention to continue, (7) in the attitude of the therapist: therapists were learned to use MI by emphasizing the autonomy of the adolescent, collaborate with them rather than taking an expert role, evoke and elicit reasons and concerns about change instead of imparting advise and, finally, to show empathy in a MI manner (Boyer et al., 2014; Kuin et al., 2013; Naar-King \& Suarez, 2011).

\begin{tabular}{|c|c|}
\hline Session & Subject \\
\hline 1 & Psycho-education and intervention goals \\
\hline 2 & $\begin{array}{l}\text { Finding new solutions for existing problems and use } \\
\text { of daily planner }\end{array}$ \\
\hline Parent 1 & Intervention content and parenting goals \\
\hline 3 & Use of to do list and prioritizing \\
\hline 4 & Dividing big problems into small steps \\
\hline 5 & $\begin{array}{l}\text { Concentration in the classroom and during } \\
\text { homework }\end{array}$ \\
\hline Parent 2 & Household rules \\
\hline 6 & Planning homework \\
\hline 7 & Help from friends and family \\
\hline 8 & Relapse prevention \\
\hline
\end{tabular}

\section{Therapists}

Three therapists provided all interventions. All three therapists are licensed behavior therapists, one of them a licensed behavior therapy supervisor and they all work at the same outpatient mental health care practice. Parents did not pay for the intervention.

\section{Outcome Measures}


Parent-reported data were collected on three outcome measures: EF problems, planning problems, and ASD characteristics. EF problems and planning problems were measured using the Dutch version of the Behavior Rating Inventory of Executive Function (BRIEF; Smidts \& Huizinga, 2009). EF problems were measured using the total score of the BRIEF questionnaire, with scores ranging from 72 to 216 . Planning problems were measured using the planning problems scale of the BRIEF, with scores ranging from 12 to 36 . On the BRIEF scales higher scores indicate more EF and planning problems. Characteristics of ASD were measured using the Dutch Autism Spectrum Quotient (AQ; Hoekstra, Bartels, Cath, \& Boomsma, 2008). In contrast to the original version of the AQ (with scores of 0 and 1) in the Dutch version a 4-point Likert scale was used. Scores on the AQ range from 50 to 200, with higher scores indicating more ASD characteristics.

\section{Expert Evaluation}

To ensure intervention adherence and to keep therapists on the same page, they met once during data collection to share experiences and to fine-tune intervention practices. After the intervention was completed, therapists met again to discuss how the intervention could be improved to best suit adolescents with ASD. These therapist evaluation meetings were recorded, coded and recommendations for intervention adaptation were formulated based on these meetings by an independent evaluator who did not provide the intervention (A.S.).

\section{Intervention Evaluation}

Both parents and adolescents were asked to evaluate their satisfaction with the intervention on three (parents) or five (adolescents) 5-point Likert scales, with higher scores indicating a more positive evaluation.

\section{Procedure}

Before pretest, both parents and adolescent gave their written informed consent. Outcome measures were collected pre- and post-intervention. Pretest took place one week before intervention and consisted of two online questionnaires for parents: the AQ and the BRIEF questionnaire. When intervention was finished, parents filled in the AQ and BRIEF and evaluated the intervention online. Adolescents evaluated the intervention after the last session of PML. During all interventions, therapists were blind for results. This study was approved by the Ethics Committee of the University of Amsterdam.

\section{Statistical analysis}

On pretest two parents accidently filled in the shortened version of the AQ, whilst we used the longer version for the other 10 parents. Therefore these missing parent scores were imputed using stochastic regression. Intention-to-treat analyses were conducted on pre- to posttest data. Outcome measures were analyzed using Reliable Change Index (RCI), classifying participants as responders when the RCI is at least 1.28 and improvement of scores was at least 1 standard deviation (Wise, 2004). Expert evaluations were investigated through qualitative analysis using Atlas.ti by an independent evaluator who did not provide the intervention (A.S.; Braun \& Clarke, 2006).

\section{Results}

Eleven adolescents completed the intervention (91.7\%), 1 adolescent dropped out after the third session because social problems were predominant rather than planning problems. RCI analyses showed that from pre- to posttest 3 adolescents improved in general EF (25.0\%), 1 in planning $(8.3 \%)$ and 3 in their ASD characteristics $(25.0 \%)$. However, most of the adolescents did not change in EF $(N=8,66.7 \%)$, planning $(N=9,75.0 \%)$ and ASD characteristics $(N=7,58.3 \%)$ and 1 adolescent even showed an increase in EF problems $(8.3 \%), 1$ in planning problems $(8.3 \%)$ and 2 in ASD characteristics (16.7\%).

Parents $(M=3.91, S D=1.04)$ and adolescents $(M=4.80, S D=.42)$ were generally positive in their evaluation of PML. Parents rated the approach that is used as positive $(M=4.09, S D=1.22)$ and they are neither positive nor negative on the benefits 
their child will have from the training in the future $(M=3.18, S D=1.08)$. Of parents $45.5 \%$ would recommend the training to other parents, $45.5 \%$ is not sure about whether to recommend it and one of the parents $(9.1 \%)$ would not recommend the training. Adolescents are satisfied with the training as it is $(M=4.60, S D=.52)$ and liked to do it $(M=$ $4.10, S D=.57)$. They evaluated the training as being useful $(M=4.70, S D=.48)$ and the workbook was rated equally positive $(M=$ $4.10, S D=.99)$. Eighty percent of adolescents expected to benefit from the training in the future and $90.0 \%$ of the adolescents would recommend the training to others.

The qualitative analysis of the expert evaluations resulted in main topics that could improve PML for an ASD sample: the approach to develop planning skills, the involvement of parents, the organization of PML, generalization of learned skills, motivational interviewing, language and wording, use of CBT, and therapeutic attitude. Based on these evaluations a detailed list of recommendations was formulated for adjustment of PML for adolescents with ASD (see Table 3).

Table 3 Recommendations for intervention revision based on expert opinion

\begin{tabular}{|c|c|}
\hline Topic & Conclusions \\
\hline Planning skills & $\begin{array}{l}\text { - Adolescents with ASD do not know how to plan their homework but are generally motivated to learn this, whereas } \\
\text { adolescents with ADHD generally know how to plan their homework but lack motivation. } \\
\text { - Adolescents with ASD need more repetition to acquire the planning skills offered. } \\
\text { - Dealing with change is one of the biggest struggles for adolescents with ASD in their daily life due to their limited } \\
\text { cognitive flexibility and should be implemented more in the sessions; also in homework planning flexibility is often } \\
\text { needed, for example when goals are not met or homework changes or takes more time than was estimated initially. } \\
\text { Dealing with change should be an additional focus of the intervention. }\end{array}$ \\
\hline $\begin{array}{l}\text { Involvement of } \\
\text { parents }\end{array}$ & $\begin{array}{l}\text { - More contact with parents is necessary than in our manual for adolescents with ADHD, to enhance generalization to the } \\
\text { home environment (this is often a key difficulty for adolescents with ASD) and increase improvement of skills. } \\
\text { - Both parental sessions should aim at finding a balance between keeping control of their child and letting go instead of just } \\
\text { one parental session (in our ADHD manual one session is on setting limits and parenting goals): autonomy is an important } \\
\text { topic for parents of adolescents that want to make their own decisions but have had difficulty with making the right } \\
\text { decisions in the past. To enhance generalization even more parental involvement may be indicated, e.g. having parents in } \\
\text { the room at the end of every session. }\end{array}$ \\
\hline $\begin{array}{l}\text { Organization of } \\
\text { intervention }\end{array}$ & $\begin{array}{l}\text { - Therapist and adolescent should build towards a complete system for planning and making homework, by using some of } \\
\text { the strategies consistently throughout all sessions. It is hard for these adolescents to integrate the different strategies into a } \\
\text { system themselves. Whereas in adolescents with ADHD the flexibility of adjusting planning strategies to their own } \\
\text { preferences is motivating, this flexibility makes it harder for adolescents with ASD. } \\
\text { - This system has to be practiced repeatedly, more than was experienced with adolescents with ADHD. }\end{array}$ \\
\hline $\begin{array}{l}\text { Generalization of } \\
\text { learned skills }\end{array}$ & $\begin{array}{l}\text { - Planning and organization strategies should be taught earlier on in the training and be repeated frequently to assure } \\
\text { generalization. } \\
\text { - The training should start with weekly sessions to teach the planning strategies, followed by monthly booster sessions with } \\
\text { parents and adolescents to enhance generalization. } \\
\text { - Parents are important as a co-therapist to improve generalization. }\end{array}$ \\
\hline $\begin{array}{l}\text { Motivational } \\
\text { Interviewing }\end{array}$ & $\begin{array}{l}\text { - Due to the limited abilities to self-reflect in ASD, motivational interviewing is less applicable than in adolescents with } \\
\text { ADHD (especially in the younger adolescents, } 12 \text { to } 14 \text { years). } \\
\text { - Most adolescent with ASD are motivated enough to do homework, but do not know how to do this homework. Enhancing } \\
\text { motivation by using motivational interviewing is therefore less needed. }\end{array}$ \\
\hline $\begin{array}{l}\text { Language and } \\
\text { wording }\end{array}$ & $\begin{array}{l}\text { - Exercises have to be formulated more direct and literally. } \\
\text { - The workbook should ask one question at a time. }\end{array}$ \\
\hline CBT & $\begin{array}{l}\text { - Cognitive techniques for maladaptive thoughts about strategies or themselves should to focus on cognitive instructing } \\
\text { rather than cognitive restructuring, due to these adolescent's problems regarding formulating cognitions. }\end{array}$ \\
\hline $\begin{array}{l}\text { Therapeutic } \\
\text { attitude }\end{array}$ & $\begin{array}{l}\text { - Therapeutic attitude needs to be direct and firm, whereby instructions are given to use strategies rather than discussing } \\
\text { strategies and their motivation for strategies (as in ADHD). } \\
\text { - Therapists have to lower the pace during the sessions in comparison to adolescents with ADHD only. } \\
\text { - As being in an intervention session can create a lot of tension in adolescents with ASD, humor is important to distract and } \\
\text { relax the adolescent even more than in ADHD. }\end{array}$ \\
\hline
\end{tabular}

Note: $A D H D$, attention deficit hyperactivity disorder; $A S D$, autism spectrum disorder; $C B T$, cognitive behavioral therapy 


\section{Clinical Case example}

James is a 13-year old boy, that was diagnosed with a pervasive developmental disorder not otherwise specified (PDD-NOS; American Psychiatric Association, 2000) when he was 8 years of age. He finds it hard to make friends, does not understand facial expressions, has problems understanding other people's feelings and is very rigid. He doesn't like changes and gets frustrated en very angry when he doesn't understand what people want from him. James can concentrate during school and whilst doing homework.

James attends a secondary school for special education. His mother referred him for the intervention at our treatment facility with the question of teaching him how to plan his home and schoolwork. James does not feel the need of following this intervention and says he doesn't have any problems with planning his home or schoolwork. His mother tells us that he simply doesn't plan at all. When teachers tell him to write down his homework for that day, he sometimes does and sometimes doesn't write it down. Once at home he only starts his homework when his mother tells him to do so. He opens his agenda en starts with the first thing he wrote down (if he wrote down anything at all). His mother tells us she has daily fights with James, about him starting his homework and about him finishing all his homework. Often he only wrote down part of the homework and he doesn't want to do more than that. James doesn't have the feeling he fights about his homework with his mother. He simply doesn't want to start and tells his mother that he doesn't want to start doing his homework.

James's mother tells us that James hasn't got any understanding of time. She plans everything for him; homework as well as his daily life. She makes a timetable including the moment he has to be ready for school and leave the house, she packs his bag for school etc. Every day, including the weekends, she plans his homework en does this homework together with him, to make sure that he doesn't forget anything. She would love to give him more responsibility and she hopes the conflicts over homework with him will stop, she really suffers and thinks these fights affect their relationship. Although James doesn't really feel the need to learn more planning skills, he agrees to start Plan My Life. To the therapist it seems like he just does what his mother tells him to do, but as he agrees to start and commit to Plan My Life they start the intervention. At pre-test James' mother reported the following scores: BRIEF total EF raw score $=143, t$-score $=$ 58 , BRIEF planning scale raw score $=24, t$-score $=$ 55 , AQ raw score $=121$.

In the first two individual sessions without his mother James doesn't seem very motivated. He has a grumpy look on his face and doesn't talk much during the sessions. He does answer all of the questions in the workbook and wants to write the answers down in his workbook himself. However, he tells the therapist that a lot of questions in the book are stupid and unnecessary. For example, he thinks that the "To Do List" is a waste of time, because he always writes "everything he has to do" in his agenda.

Because Plan My Life is based on motivational interviewing all the skills taught in the manual are presented as a new experiment, with the aim of ensuring that the adolescent has autonomy in their own intervention. The adolescent can choose whether he/she wants to try this new skill, also he/she evaluates what the costs and benefits are for them, all to enhance their own motivation for change. In the first two sessions James often chooses not to try a new skill, he just doesn't see that he has a problem. Also, in Plan My Life adolescents can choose their own intervention goals to work on to enhance autonomy and their need for independence and eventually enhance their motivation for change. James tends to set very high goals for himself, almost impossible to reach. For example, he formulated the following intervention goal: "To start and finish my homework every day without any help". He doesn't know how to divide these high goals into smaller steps and doesn't accept the attempts of the therapist to help him with that.

All in all, although James attends the first two sessions of intervention, James does not seem motivated and seems to shows resistance. The techniques from motivational interviewing (e.g. giving choice and autonomy, formulating whether you want to change and what you want to change) do not enhance his motivation for change. James 
finds it difficult to self-reflect and lacks the cognitive flexibility to change perspective on his own role in this home/schoolwork situation. Because of the problems experienced during the first two sessions, the therapist asks James if his mother could be involved in the next session. James gives permission for his mother's presence.

In the third session, the therapist tells James' mother and James that she notices James has problems trying new things and asks her if she has any ideas on strategies how to help him. James' mother has some ideas and it turns out James accepts her ideas better than the ones in the workbook or the ones from the therapist. The strategies his mother presents are quite similar to the ones presented in the workbook and the one formerly proposed by the therapist, however coming from his mother James is inclined to try them.

It looks like James has a strong connection with his mother and he feels more safe to try new things with her approval. Providing the intervention in this manor with his mother seems to require less cognitive flexibility for him as the situation is similar to his regular routine (his mother being involved in his homework and telling him what to do). Therefore it was decided to give her a more prominent role and involve her at the end of every session. As one of the intervention goals is to support James' independence, still a part of the session will be without his mother. Also, during the sessions the therapist used a more instructional style. From that moment on James talks more during the sessions (also when his mother is not there) and is more active in thinking about other solutions for his planning problems, he actually now sees planning problems himself as well. Knowing that his mother will be there at the end of the session is very motivating for him. Also, it helps to know more about the way things work at home with her input. The therapist has an investigative role when she talks with James and his mother. She focuses on the feasibility of the strategies and how to specifically integrate them at home in their daily routine. Some new skills are easy to integrate at home, like starting with his homework without his mother pushing him to do so. This is accomplished by making a clear schedule and rules about the starting time of this homework together with James and his mother. Other skills, like dividing his homework over the day instead of trying to do it all at once, take several weeks as they are clearly more difficult and require more cognitive flexibility of James. After mutual consent of mother and James the intervention is ended.

At post-test James' mother reported the following scores: $B^{2} I E F_{\text {total }}$ EF raw score $=160$, BRIEF $_{\text {total EF t-score }}=64$, BRIEF $_{\text {planning scale raw score }}=26$, $\mathrm{BRIEF}_{\text {planning scale t-score }}=58, \mathrm{AQ}_{\text {raw score }}=131$. Reliable change index shows James deteriorated on total executive functioning $\left(\mathrm{BRIEF}_{\text {total }} \mathrm{EF}_{\mathrm{RCI}}=1.75\right)$, remained the same on planning skills $\left(\mathrm{BRIEF}_{\text {planning }}\right.$ scale $\mathrm{RCI}=0.79$ ) and deteriorated on ASD symptoms $\left(\mathrm{AQ}_{\mathrm{RCI}}=1.30\right)$ during the intervention with PML.

After the intervention, his mother says that James checks more often if he needs to do homework without her reminding him and he starts doing homework himself without help from mother. Also, there are fewer fights at home about doing homework. However, other skills are not acquired yet; for example James is not able to pack his schoolbag himself. Mother says she sees the intervention as a small step on the long road to independence for James. James himself likes that there are less fights about homework. He does experience that for example dividing his homework over the day leads to better grades. Therefore he doesn't like dividing his homework over the day and doesn't know if he wants to continue doing it after intervention is finished. Nevertheless, he would recommend the intervention to others.

Working together with James and his mother is a big contrast compared to how regularly planning focused CBT works with adolescents with ADHD and their parents; adolescents with ADHD are often very happy to have less involvement from their parents and more autonomy in their homework and their sessions. Also, the more instructional style as used with James and his mother, can be contra-productive with adolescents with ADHD as it restricts their need for autonomy. 


\section{Discussion}

From a clear clinical need (parents of and adolescents with ASD often ask for a planning and organization intervention) and overlap in daily life impairments in planning and organization we provided a cognitive behavioral planning and organization originally developed for adolescents with ADHD to adolescents with ASD. Our pilot study clearly shows that a planning and organization intervention for adolescents with ADHD cannot be easily transposed to adolescents with ASD. Even though parents and adolescents were positive about PML and attrition was low, in this small sample of 12 adolescents most of them did not improve in EFs or planning skills during intervention. The lack of improvement of EF and planning problems between pre- and posttest is remarkable given the improvements with large effect sizes seen in adolescents with ADHD who received PML (Boyer et al., 2014) and the overlap between both groups in planning problems in their daily life school life.

One explanation might be that in our small sample, half of our ASD sample did not have planning problems within the clinical range (on the BRIEF questionnaire) at baseline, according to their parents. Furthermore, because most participants attended special education designed for adolescents with an ASD, they probably already got assistance at school aimed at their specific disabilities, including homework problems. This could imply that our sample did not have enough room for improvement to show intervention effects. However, parents and adolescents applied for intervention focused on enhancement of planning skills themselves, indicating that they still experienced problems with planning in their daily life. Moreover, when repeating analyses on only the adolescents that did show $\mathrm{EF}(N=7)$ and planning problems $(N=6)$ within the clinical range at baseline, still no intervention effects were found $\left(N_{\mathrm{EF}}=0\right.$ improved, $N_{\mathrm{EF}}=0$ deteriorated; $N_{\text {planning }}=0$ improved, $N_{\text {planning }}=$ 2 deteriorated) indicating that in it's current form PML does not seem suitable for adolescents with ASD.

Almost half of our sample had co-existing ADHD, which is not only associated with higher autistic traits than children with ASD only (Sprenger et al., 2013), but also with more attention problems than children with ADHD only (Sinzig et al., 2009). In addition, adolescents with ASD suffer from significant impairments in planning and organizing, which appear to be even more impairing than in ADHD only (Hill, 2004). As ASD an ADHD often occur together, our sample seems representative for adolescents with ASD (Sinzig et al., 2009) and potentially has more severe difficulties than a sample of adolescents with ADHD alone. This could imply that more intensive intervention is necessary for adolescents with ASD to cause improvement as compared with adolescents with ADHD only. This is supported by the expert recommendations regarding the need for booster sessions to follow-up learned skills to enhance generalization.

In addition to the need for prolonged intervention, analyses of expert evaluations gave a feasible list of recommendations for adjustment of this intervention to the needs of this particular group as compared to adolescents with ADHD (but without ASD). Some examples are; greater need for parents to enhance generalization, a more structured intervention and clear wording in the workbook, less use of motivational interviewing and a more direct therapeutic attitude. Finally, to enhance generalization of learned skills it is advised to implement the intervention at home or in schools. These recommendations emphasize the differences between adolescents with ADHD and ASD and the need for specialized intervention approaches.

Finally, this was a pilot-study with a small sample. Further research should include a larger, more heterogeneous sample (special education as well as regular schools) and an adapted form of PML according to the formulated recommendations. These recommendations seem specific to the ASD sample and may be applicable to other non-pharmacological interventions that will be developed for individuals with ASD to improve their care and outcomes.

\section{References}

American Psychiatric Association (2000). Diagnostic and statistical manual of mental disorders (4th ed., text rev.). Washington, DC: Author. 
doi:10.1176/appi.books.9780890423349.

Begeer, S., Wierda, M., \& Venderbosch, S. (2013). NVA enquête 2013: Allemaal autisme, allemaal anders. De Bilt, The Netherlands: Nederlandse Vereniging voor Autisme.

Boyer, B. E., Geurts, H. M., Prins, P. J. M., \& Van der Oord, S. (2014). Two novel CBTs for adolescents with ADHD: The value of planning skills. European Child and Adolescent Psychiatry, 24, 1075-1090. doi: 10.1007/s00787-014-0661-5

Boyer, B. E., Geurts, H. M., Prins, P. J. M., \& Van der Oord, S. (2015). One-year follow-up of two novel CBTs for adolescents with ADHD. European Child and Adolescent Psychiatry, 25(3), 333-337. doi: 10.1007/s00787-0150776-3.

Braun, V., \& Clarke, V. (2006). Using thematic analysis in psychology. Qualitative Research in Psychology, 3, 77101.

Endedijk, H., Denessen, E., \& Hendriks, A. W. (2011). Relationships between executive functioning and homework difficulties in students with and without autism spectrum disorder: An analysis of student- and parentreports. Learning and Individual Differences, 21, 765-770.

Demetriou, E. A., Lampit, A., Quintana, D. S., Naismith, S. L., Song, Y. J. C., Pye, J. E., Hickie, I., \& Guastella, A. J. (2018). Autism spectrum disorders: A meta-analysis of executive function. Molecular Psychiatry, 23, 1198-1204. doi: $10.1038 / \mathrm{mp} .2017 .75$

Geurts, H. M., Verté, S., Oosterlaan, J., Roeyers, H., \& Sergeant, J. A. (2004). How specific are executive functioning deficits in attention deficit hyperactivity disorder and autism? Journal of Child Psychology and Psychiatry, 45, 836-854. doi:10.1111/j.14697610.2004.00276.x

Hoekstra, R. A., Bartels, M., Cath, D. C., \& Boomsma, D. I. (2008). Factor structure, reliability and criterion validity of the Autism-Spectrum Quotient (AQ): A study in Dutch population and patient groups. Journal of Autism and Developmental Disorders, 38, 1555-1566. doi: 10.1007/s10803-008-0538-x

Kort, W., Schittekatte, M., Dekker, P. H., Verhaeghe, P., Compaan, E. L., Bosmans, M., \& Vermeir, G. (2005). Wechsler Intelligence Scale for Children-III: Handleiding. Amsterdam, The Netherlands: Pearson.

Kuin, M., Boyer, B. E., \& Van der Oord, S. (2013). Zelf Plannen [Plan My Life]. Houten, The Netherlands: Uitgeverij Lannoo-Campus.

Naar-King, S. \& Suarez, M. (2011). Motivational interviewing with adolescents and young adults. New York, NY: The Guilford Press.

Rosenthal, M., Wallace, G. L., Lawson, R., Wills, M. C., Dixon, E., Yerys, B. E., \& Kenworthy, L. (2013). Impairments in real-world executive function increase from childhood to adolescence in autism spectrum disorders. Neuropsychology, 27 (1), 13-18. doi: 10.1037/a0031299

Sinzig, J., Walter, D., \& Doepfner, M. (2009). Attention Deficit/Hyperactivity Disorder in children and adolescents with autism spectrum disorders: Symptom or syndrome?
Journal of Attention Disorders, 13, 117-126. doi: $10.1177 / 1087054708326261$

Smidts, D. P. \& Huizinga, M. (2009). Handleiding Executieve Functies, Gedragsvragenlijst. Amsterdam, The Netherlands: Hogrefe.

Sprenger, L., Bühler, E., Poustka, L., Bach, C., HeinzelGutenbrunner, M., Kamp-Becker, I., \& Bachmann, C. (2013). Impact of ADHD symptoms on autism spectrum disorder symptom severity. Research in Developmental Disabilities, 34, 3545-3552. doi: 10.1016/j.ridd.2013.07.028

Welsh, M. C., \& Pennington, B. F. (1988). Assessing frontal lobe functioning in children: Views from developmental psychology. Developmental Neuropsychology, 4, 199-230. doi: 10.1080/87565648809540405

Wise, E. A. (2004). Methods for analyzing psychotherapy outcomes: A review of clinical significance, reliable change, and recommendations for future directions. Journal of Personality Assessment, 82(1), 50-59. doi: 10.1207/s15327752jpa8201_10. 